\title{
Erratum to: Heavy metal contamination in feathers of Western Reef Heron (Egretta gularis) and Siberian gull (Larus heuglini) from Hara biosphere reserve of Southern Iran
}

\author{
Borhan Mansouri • Alireza Pourkhabbaz • \\ Hadi Babaei • Ebrahim Hoshyari
}

Published online: 21 July 2012

(C) Springer Science+Business Media B.V. 2012

\section{Erratum to: Environ Monit Assess}

DOI 10.1007/s10661-011-2408-9

The original version of this article unfortunately contained an error. One of the authors, Alireza Pourkhabbaz was missing from the author list. The complete list of authors is shown above

The new corresponding author is Ebrahim Hoshyari. Complete information is shown below.

The online version of the original article can be found at http://dx.doi.org/10.1007/s10661-011-2408-9.

B. Mansouri

Young Researchers Club, Kermanshah Branch, Islamic Azad University,

Kermanshah, Iran

e-mail: borhanmansouri@yahoo.com

\footnotetext{
A. Pourkhabbaz $\cdot$ E. Hoshyari $(\bowtie)$

Department of Environmental Sciences,

Faculty of Agriculture, Birjand University,

Birjand, Iran

e-mail: ebrahimhoshiari@gmail.com

H. Babaei

Inland Water Aquaculture Research Institute,

P.O. Box: 66, Port Anzali, Iran

e-mail: babaeiha@yahoo.com
} 